\title{
A fine fraction of soil used as an aerosol analogue during the DUNE experiment: sequential solubility in water, decreasing pH step-by-step
}

\author{
C. Aghnatios ${ }^{1}$, R. Losno ${ }^{1, *}$, and F. Dulac ${ }^{1,2}$ \\ ${ }^{1}$ Laboratoire Interuniversitaire des Systèmes Atmosphériques (LISA), UMR7583 CNRS-INSU, University Paris 7 Denis \\ Diderot, University Paris-Est Créteil, France \\ ${ }^{2}$ Laboratoire des Sciences du Climat et de l'Environnement (LSCE), UMR8212 CEA-CNRS-UVSQ-CEA Saclay 701, 91191 \\ Gif-sur-Yvette CEDEX France \\ * now at: Institut de Physique du Globe de Paris (IPGP), Sorbonne Paris Cité, University Paris 7 Denis Diderot, UMR7154 \\ CNRS, 75005 Paris, France
}

Correspondence to: R. Losno (losno@ipgp.fr)

Received: 26 December 2013 - Published in Biogeosciences Discuss.: 13 February 2014

Revised: 20 June 2014 - Accepted: 18 July 2014 - Published: 2 September 2014

\begin{abstract}
A soil sample collected in a desert aerosol source area near Douz (southern Tunisia) was dry-sieved at $20 \mu \mathrm{m}$ in order to extract the fraction similar to a wind-generated aerosol, and was used to seed mesocosms during the DUNE experiment (a DUst experiment in a low Nutrient, low chlorophyll Ecosystem). In this work, said "aerosol-like" fine dust was sequentially leached by short contacts with water at initial pHs, decreasing from seven to one, representing various wet environmental conditions. For each step, the solubility of a given element is calculated as the amount of its dissolved fraction, relative to its total amount. The evolution of this fractional solubility from the highest to lowest pHs provides information on the chemical strength needed to solubilise a given element and its lability. The behaviour of the elemental solubility was sorted into two groups: (1) $\mathrm{Ca}, \mathrm{Sr}$, $\mathrm{Ba}, \mathrm{Mn}$, and $\mathrm{P}$, with a solubility between $23 \%$ and $70 \%$, and a maximum sequential solubility at $\mathrm{pH} 3$; (2) $\mathrm{Al}$ and $\mathrm{Fe}$, with a solubility of less than $2 \%$ and the highest release at $\mathrm{pH}$ 1. Similar solubility patterns in group 1 for $\mathrm{Ca}, \mathrm{P}$, and $\mathrm{Mn}$ suggest a possible association of the elements in the same minerals, most probably carbonates.
\end{abstract}

\section{Introduction}

The DUNE experiment (Guieu et al., 2010, 2014) used the finest fraction of an alluvial soil collected in southern Tunisia $\left(33.452^{\circ} \mathrm{N}, 9.335^{\circ} \mathrm{E}\right)$, a region known to provide the western Mediterranean Basin with mineral dust aerosol (Bergametti et al., 1989). This soil fraction was considered a model of natural atmospheric Saharan dust and was used to seed mesocosms in order to observe the influence of Saharan dust input on the biogeochemistry of the Mediterranean Sea (Guieu et al., 2010). This soil fraction was mainly a mixture of quartz, calcite and clays (Desboeufs et al., 2014). Knowledge of elemental solubility is key to assessing the impact of atmospheric deposition and the impact of particle material added into a mesocosm. The word "solubility" covers many different meanings and different protocols, as explained in Sholkovitz et al. (2012) in the case of iron. In this paper on fractional solubility, we discuss the amount of soluble element divided by the total amount of the element present in the soluble and insoluble phases. The soluble-fraction separation method is described in Sect. 2.

Solubility experiments are generally carried out using ultra-pure water or freshly collected surface seawater (Buck et al., 2013) or a buffered solution at pH 4.7 (Baker et al., 2006). Solubility could also be more than a simple single value; for example, a list of values respectively associated with a set of successive extraction protocols (Gleyze et al., 
2002, Filgueiras et al., 2002). These different values link the dissolution of an element to its binding and its mineralogical form in the solid. Here, we report the results of an experiment based on the successive leaching of small masses of particles used for the DUNE experiment. Cloud processed (used in DUNE-P and DUNE-R) and non-processed (used in DUNEQ) dust analogues were used to arteficially seed large mesocosms (Desboeufs et al., 2014). The cloud-processed dust samples have been put into contact with synthetic cloud water in the laboratory (Guieu et al., 2010). The leaching tests reported here were performed on the non-processed dust analogue, which has not been modified. We performed the leaching using water solutions with increasing acidity in order to measure the lability of the elements in the pristine dust, as well as to investigate the fate and behaviour of such dust in various wet environments, including non-polluted rainwater at high pHs and cloud polluted droplets at low pHs.

\section{Experimental protocol}

All operations described here took place in an ISO-6 clean room with thoroughly washed labware. Bottles and devices that were in contact with the samples were washed using dish detergent, then soaked for at least one day in a $2 \%$ $\operatorname{Decon}^{\mathrm{TM}}$ (lab detergent) bath, prepared with osmosed water, carefully rinsed, soaked for one week in $2 \%$ hydrochloric acid in osmosed water, rinsed again with ultra-pure water $\left(\right.$ Elgapure $\left.^{\mathrm{TM}}\right)$, soaked for at least one month in high purity $2 \%$ hydrochloric acid (Meck ${ }^{\mathrm{TM}}$, Suprapur ${ }^{\mathrm{TM}}$ grade), diluted with ultra-pure water, and finally rinsed with ultra-pure water and left to dry in a laminar flow bench (ISO-1).

The dried collected soil was, first of all, gently crushed and then dry-sieved using nylon meshes. The fraction, which passed through the $20 \mu \mathrm{m}$ mesh, was mixed in a unique batch and used as a mineral dust aerosol analogue for the DUNE experiments. Details are provided in Guieu et al. (2010). Approximately $10 \mathrm{mg}$ of this dust analogue was deposited on a $47 \mathrm{~mm}$ diameter and $0.2 \mu \mathrm{m}$ porosity polycarbonate membrane in a polycarbonate filtration device $\left(\right.$ Nalgene $\left.{ }^{\mathrm{TM}}\right)$. Leaching solution $(100 \mathrm{~mL})$ was then poured onto the filter, gently stirred by hand and left for 1 minute. After this delay, a vacuum was applied to the filtration unit until all of the solution had passed through, which took approximately $20 \mathrm{~s}$ more. In all, $10 \mathrm{~mL}$ was set aside for $\mathrm{pH}$ determination, and $60 \mathrm{~mL}$ was stored in a polyethylene bottle, the $\mathrm{pH}$ having decreased to 1 with ultra-pure nitric acid (Merck, Suprapur ${ }^{\mathrm{TM}}$ grade). Twelve successive leaching steps were applied to the same filter with increasing acidity solutions, following the leaching literature (e.g. Filgueiras et al., 2002; Gleyzes et al., 2002). Nitric acid (Merck, Suprapur) and ultra-pure water were used to prepare the acidic water solutions. The first three leaching steps used simple ultra-pure water $(\mathrm{pH} \sim 6.5$, lower than 7 due to ambient $\mathrm{CO}_{2}$ dissolution; hereafter referred as " $\mathrm{pH} 7$ "), the following three used $10^{-5} \mathrm{M}$ acid so- lution ("pH 5"), followed by three steps with $10^{-3} \mathrm{M}$ acid solution ("pH 3"), and finally, three steps with $10^{-1} \mathrm{M}$ acidic solution ("pH 1"). Four replicate experiments were carried out with the same conditions.

Analyses were performed by ICP-AES (Perkin Elmer, Optima 3000) with a CETAC ultrasonic nebulisation, as described in Desboeufs et al. (2003) for the elements dissolved in the solution after leaching. The following elements were determined using the atomic emission line (wavelength in brackets, nm): $\mathrm{Ca}$ (422.673), $\mathrm{Sr}$ (407.771), Ba (455.403), Mn (257.61), Fe (259.94), Al (396.152), and P (213.628). The instrument was calibrated on each line using standard solutions, and was checked five times with the certified reference material (CRM) SLRS-4 (NRC, Canada, certified values reported in Yeghicheyan et al., 2001 or Heimburger et al., 2013). P is not certified in this CRM. An indicative concentration was published in Yeghicheyan et al. (2001), but a more recent value $[\mathrm{P}]_{4}$ was retrieved from the SLRS-5/SLRS-4 concentration ratio $R_{\mathrm{P}}$ published in $\mathrm{He}-$ imburger et al. (2013), and its concentration $[\mathrm{P}]_{5}$ in SLRS5 published in Yeghicheyan et al. (2013). These values are respectively equal to $R_{\mathrm{P}}=1.43 \pm 0.02$ and $[\mathrm{P}]_{5}=8.2 \pm$ $3 \mu \mathrm{g} \mathrm{L}{ }^{-1}$. The deduced concentration in SLRS-4 is found to be $[\mathrm{P}]_{4}=[\mathrm{P}]_{5} / R_{\mathrm{P}}=5.7 \pm 2 \mu \mathrm{g} \mathrm{L}^{-1}$. The recovery rate was found to be between 97 and $120 \%$ for the certified elements $\mathrm{Ca}, \mathrm{Sr}, \mathrm{Ba}, \mathrm{Mn}, \mathrm{Fe}$, and $\mathrm{Al}$, and $96 \%$ for $\mathrm{P}$ using the recalculated value $[\mathrm{P}]_{4}$. P calibration solutions were also checked by measuring a dilution by 10 of a $10 \mathrm{ppm}$ commercial solution (Thermo Elemental ICAP calibration solution) independent of the calibration solutions, and an accuracy of $2 \%$ was found for this check. The relative standard deviations for the five SLRS-4 replicated measurements were less than $5 \%$, except for $\mathrm{P}$, where it reached $10 \%$. The analytical detection limit (DL) for one measurement was determined for each element as three times the standard deviation of the analytical blanks, converted into the quantities present in $100 \mathrm{~mL}$ of solution, and expressed as the percentage of the element present in $10 \mathrm{mg}$ of soil. Because the final results were an average of four experimental replicates, the detection limit value for a single measurement was divided by the square root of four (two) to take into account the averaging effect. The DL values are reported on the last line in Table 2.

To test the cleanliness of the protocol and evaluate the experimental detection limit of the analyses, we made two blanks by leaching the pristine filters only. All these experimental blanks were below the detection limit so that the experimental detection limit was equal to the analytical detection limit.

Elemental analyses of the soil were performed by Xray fluorescence (Pan Analytical 2400) after calcination at $1050^{\circ} \mathrm{C}$ and lithium tetraborate/metaborate fusion. Major and minor elements were determined using geostandards (BX-N, BE-N, ST-N from SARM, Nancy, France) for calibration. $\mathrm{Ba}$ and $\mathrm{Sr}$ were measured by ICP-AES after acid 
digestion (Desboeufs et al., 2014 for Sr, K. Desboeufs, personal communication, 2011 for $\mathrm{Ba}$ ).

Finally, the solubility was expressed in a given leaching batch as the amount of element found in the $100 \mathrm{~mL}$ of solution, which passed through the filter divided by the total amount of element initially present in the soil mass used for the experiment. This solubility can be called the "relative fractional solubility". A cumulative solubility was also calculated as the sum of the successive batch dissolution experiments performed up until the given batch. The average results of the four replicates with associated uncertainty are displayed in Table 2. We can see in this table that most of the uncertainty for the dissolution step is due to the DL.

\section{Results and discussion}

The elemental composition of the soil is given in Table 1 and is expressed as oxides for the major elements, except for calcium, which is associated with carbonate. The last column of the table displays the composition as elements, including $\mathrm{Sr}$ and $\mathrm{Ba}$, which are present at trace levels. The median and standard deviation results of the four replicates, including the measured $\mathrm{pHs}$, are given in Table 2.

Large amounts of calcite were found in the sample (Desboeufs et al., 2014) and the amount of calcium carbonate explained the ignition loss well with its transformation into calcium oxide and carbon dioxide exhaust. The southern Tunisian source region is known to produce calcium-rich dust (Bergametti, 1989; Avila et al., 2007) due to the carbonated lithology of the soils in this region (Claquin et al., 1999). High calcite concentrations were measured in the dust originating from Tunisia, northern and central Algeria, and Morocco, and low concentrations occur south of, approximately, $27^{\circ} \mathrm{N}$ (Kandler et al., 2007).

The $\mathrm{pH}$ of each leaching solution was measured at the end of each dissolution batch and exhibits modifications from the original $\mathrm{pH}$ because of the alkalinity of the soil. This alkalinity can be attributed to carbonate dissolution:

$$
\begin{aligned}
& \mathrm{CaCO}_{3}+\mathrm{H}^{+}=\mathrm{HCO}_{3}^{-}+\mathrm{Ca}^{2+} \text { at } \mathrm{pH}>6 \text { and } \\
& \mathrm{CaCO}_{3}+2 \mathrm{H}^{+}=\mathrm{CO}_{2}+\mathrm{Ca}^{2+}+\mathrm{H}_{2} \mathrm{O} \text { for lower pHs. }
\end{aligned}
$$

Table 2 summarises the obtained results. For the three successive dissolution experiments with the same leaching solution, no noticeable $\mathrm{pH}$ variations were observed. For pure water, the $\mathrm{pH}$ was buffered around 8 . By increasing the acidity of the leaching solution, the $\mathrm{pH}$ decreased to 6.7 for the "pH 5" leaching solution; with the "pH 3" solution, the end of the buffering capacity of the solid was reached with a measured $\mathrm{pH}$ equal to 3.0. At this $\mathrm{pH}$ of 3 , a maximum calcium release was observed for the first leaching process (Fig. 1a), strengthening the hypothesis that calcium was mainly present as calcium carbonate in the solid. The most acidic solution, "pH 1", was measured at $\mathrm{pH} 1.1$.

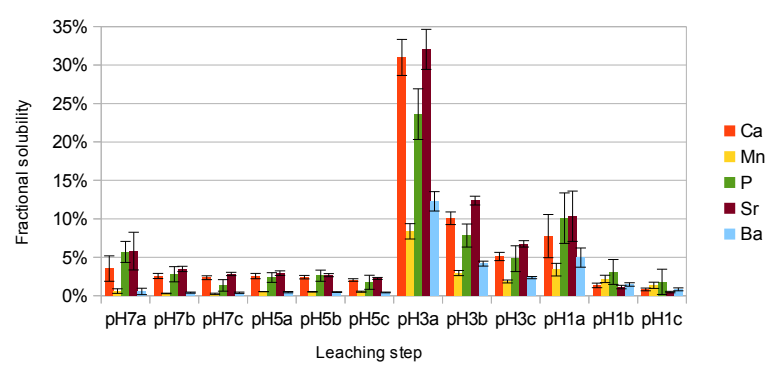

a)

b)

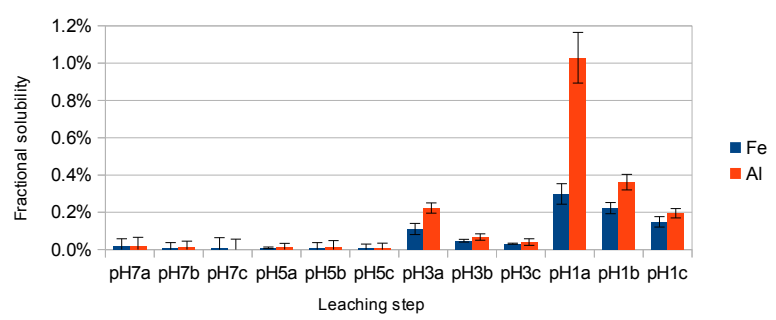

Figure 1. Average fractional solubility relative to the initial quantity of element measured for each leaching step from $\mathrm{pH7a}$ to $\mathrm{pH} 1 \mathrm{c}$ for each group. (a) $\mathrm{Ca}, \mathrm{Mn}, \mathrm{P}, \mathrm{Sr}, \mathrm{Ba}$ (group 1), (b) $\mathrm{Al}$ and $\mathrm{Fe}$ (group 2). The segments are the standard deviation of the four replicated experiments. The corresponding measured $\mathrm{pHs}$ for batches " $\mathrm{pH} 7$ ", "pH 5", "pH 3", and "pH 1" are 8, 6.7, 3, and 1.1, respectively.

A first dissolution pattern is displayed in Fig. 1a. For Ca, $\mathrm{Sr}$, and $\mathrm{P}$, the solubility was approximately $5 \%$ for the first leaching batch at $\mathrm{pH} 8$, and it continuously decreased until reaching the first " $\mathrm{pH} 3$ " leaching solution, for which it increased up to $30 \%$ for $\mathrm{Ca}$. After this $\mathrm{pH}$, the solubility decreased again, except during the first leaching with a solution at $\mathrm{pH}$ 1. The pattern was the same for $\mathrm{Ba}$ and $\mathrm{Mn}$, but with a solubility that was three times lower than that for the other elements at each step, except for that at $\mathrm{pH} 1$, for which the solubilities of all displayed elements were of the same order of magnitude. Both Filgueiras et al. (2002) and Gleyzes et al. (2002) pointed out carbonate dissolution with a mild acid reagent, which occurs at pH 5 and below. With our experiments, $\mathrm{pH} 5$ was not reached by the leaching solution labelled "pH 5" because of the alkalinity of the soil, which overcame the unbuffered acidity of the leaching solution. The solution labelled "pH 3" was the first one that was acidic enough to dissolve carbonates. Here, $\mathrm{Mn}, \mathrm{Sr}$, $\mathrm{Ba}$, and $\mathrm{P}$ seem to be strongly linked to calcium carbonate. This is not surprising for $\mathrm{Sr}$ and $\mathrm{Ba}$, which both belong to the same periodic-table column, as Ca. Kitano et al. (1978) found phosphorus uptake by calcium carbonate in seawater and fresh water. Released phosphorus may be one element that has been incorporated into the carbonate during its formation period. Plotting the phosphorus cumulative dissolution as a function of the calcium cumulative dissolution, a 
Table 1. Elemental composition of the soil for the major and minor elements. Sr and Ba are from Desboeufs et al. 2014, $Q$ sample for $\mathrm{Sr}, \mathrm{R}$ for $\mathrm{Ba}$ ). The right column, written in italics, is the elemental composition.

\begin{tabular}{llll}
\hline Compound & $\begin{array}{l}\text { Composition } \\
\text { (as oxide) }\end{array}$ & $+/-$ & $\begin{array}{l}\text { Composition } \\
\text { (as element) }\end{array}$ \\
\hline $\mathrm{SiO}_{2}$ & $33.0 \%$ & 0.7 & $15.4 \%$ \\
$\mathrm{Al}_{2} \mathrm{O}_{3}$ & $8.9 \%$ & 0.4 & $4.7 \%$ \\
$\mathrm{Fe}_{2} \mathrm{O}_{3}$ & $3.3 \%$ & 0.3 & $2.3 \%$ \\
$\mathrm{MnO}_{2}$ & $0.055 \%$ & 0.002 & $0.035 \%$ \\
$\mathrm{MgO}$ & $3.5 \%$ & 0.1 & $2.1 \%$ \\
$\mathrm{CaCO}_{3}$ & $49 \%$ & 2 & $19.6 \%$ \\
$\mathrm{Na}_{2} \mathrm{O}$ & $<1 \%$ & - & $<1 \%$ \\
$\mathrm{~K}_{2} \mathrm{O}$ & $1.72 \%$ & 0.05 & $1.4 \%$ \\
$\mathrm{TiO}_{2}$ & $0.54 \%$ & 0.01 & $0.32 \%$ \\
$\mathrm{P}_{2} \mathrm{O}$ & $0.10 \%$ & 0.01 & $0.044 \%$ \\
$\mathrm{Sr}$ & & & $360 \pm 27 \mathrm{ppm}$ \\
$\mathrm{Ba}$ & & & $270 \pm 14 \mathrm{ppm}$ \\
\hline
\end{tabular}

straight line with a slope of 0.86 is obtained by least-squares regression (Fig. 2a). This suggests a linked dissolution of calcium and phosphorus for all batches and therefore provides strong evidence for the association of soluble phosphorus with calcium carbonate in the same solid phases. This type of association between calcium and phosphorus in Saharan dust was reported in Nenes et al. (2011) who found that between 50 and $70 \%$ of phosphorus is associated with calcium using a specific Ca-bond-P extraction method. These authors decided on the presence of apatite, because they never hypothesised an association between calcite and phosphorus, yet the protocol they used extracted calcite as well. However, Nezat et al. (2007) reported that apatite does not dissolve well in silicated soils with $0.1 \mathrm{M}$ nitric acid solution, and a $1 \mathrm{M}$ concentration is necessary to prevent the absorption of $\mathrm{P}$ onto aluminium or iron oxides. They also suggested the presence of fluoroapatite in carbonate minerals. The experiments, presented here on calcite-rich soil, revealed the importance of phosphorus associated with carbonate, which followed the same dissolution pattern.

Fujiwara (1964) found manganese as single $\mathrm{Mn}^{2+}$ ions randomly distributed in natural calcium carbonate lattices. In Fig. 2b, we can observe the same behaviour for manganese as for phosphorus, but with a linear-regression slope equal to 0.27 . The values obtained for the $\mathrm{pH} 1$ leaching step were excluded from the regression because they were above the line. We can conclude that part of manganese was closely associated with calcium carbonate and was released with calcium for $\mathrm{pHs}$ higher than or equal to 3 . At $\mathrm{pH} 1$, solid phases that were different from calcium carbonate released manganese. Aluminium and iron belong to a second group of elements. Indeed, the dissolution of both these elements was very low (max. $0.2 \%$ ) until $\mathrm{pH} 3$, and then it increased up to $1 \%$ for aluminium and $0.4 \%$ for iron at $\mathrm{pH} 1$ (Fig. 1b).

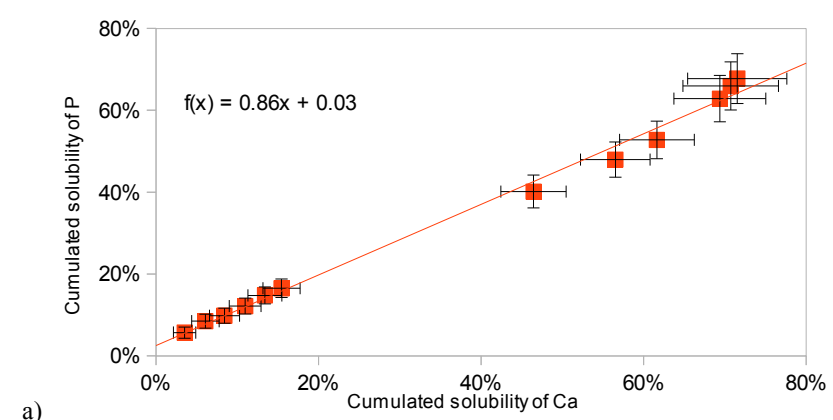

a)

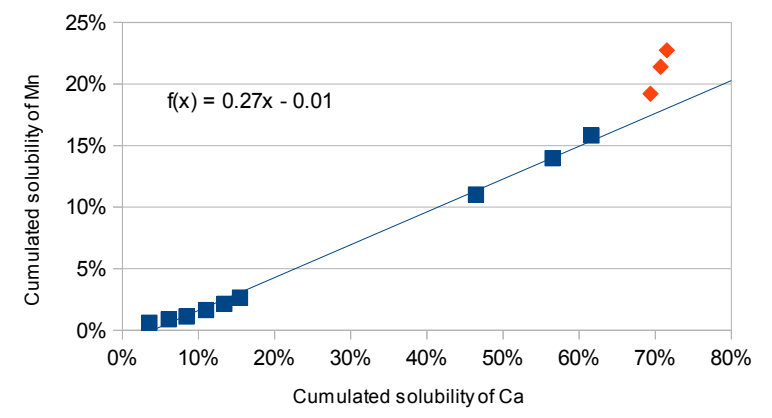

b)

Figure 2. Cumulated solubility of (a) $\mathrm{P}$ and (b) $\mathrm{Mn}$ as a function of the cumulated solubility of $\mathrm{Ca}$. The plotted line is a least-squares linear regression. The three orange points for $\mathrm{Mn}$ are not included in the regression and were obtained at $\mathrm{pH} 1$.

At a given $\mathrm{pH}$, a strong decrease was always observed from the first to the third leaching step (labelled in order as a, $\mathrm{b}$, and c) without a noticeable measured $\mathrm{pH}$ variation. We can therefore assume that there is a finite stock of elements that can be dissolved at each tested $\mathrm{pH}$. The dissolution percentages measured for each repeated $\mathrm{pH}$ can thus be added. We can also calculate a cumulative solubility for each $\mathrm{pH}$ that represents the amount that would be rapidly dissolved at the given $\mathrm{pH}$. The cumulative dissolutions of $\mathrm{Al}, \mathrm{Fe}, \mathrm{Mn}$, and $\mathrm{P}$ are displayed in Fig. 3. Elements belonging to group $1(\mathrm{Mn}$, $\mathrm{P})$ are much more soluble than those belonging to group $2(\mathrm{Al}$ and $\mathrm{Fe}$ ), and two scales are necessary to display both groups on the same figure.

The very low solubility of $\mathrm{Al}$ and $\mathrm{Fe}$ at the highest $\mathrm{pHs}$ was already observed for the Saharan dust analogue, e.g. for Saharan losses collected in Cape Verde (Desboeufs et al., 1999). The solubility is reported as slightly higher ( 3 and $1.7 \%$ respectively) by Baker et al. (2006) for Saharan dust collected over the Atlantic. This increase in solubility from pristine soil to aerosol is attributed by Baker et al. (2006) and Desboeufs et al. (2001) to ageing and acid processing in clouds. This behaviour was also observed in our sample, where an acid processing at $\mathrm{pH} 1$ increased the aluminium and iron solubility near to the values proposed by Baker at al. (2006) 
Table 2. Final $\mathrm{pH}$ and relative fractional solubility of each measured element for each leaching step. The associated uncertainty of the averaged measurements is calculated as three times the standard deviation of the four replicates divided by the square root of 4 , the number of replicates. The uncertainty of cumulated dissolution should be calculated as the square root of the sum of the square of all previous dissolution steps.

\begin{tabular}{|c|c|c|c|c|c|c|c|c|}
\hline $\begin{array}{c}\text { Sample } \\
\text { name }\end{array}$ & $\begin{array}{c}\text { Measured } \\
\text { final } \mathrm{pH}\end{array}$ & $\begin{array}{r}\mathrm{Ca} \\
\text { fraction }\end{array}$ & $\begin{array}{r}\mathrm{Sr} \\
\text { fraction }\end{array}$ & $\begin{array}{r}\mathrm{Ba} \\
\text { fraction }\end{array}$ & $\begin{array}{r}\text { Mn } \\
\text { fraction }\end{array}$ & $\begin{array}{r}\mathrm{Fe} \\
\text { fraction }\end{array}$ & $\begin{array}{r}\text { Soluble } \\
\text { Al fraction }\end{array}$ & $\begin{array}{r}\text { Soluble } \\
\text { P fraction }\end{array}$ \\
\hline \multicolumn{9}{|c|}{ Averaged fractional solubility values on the 4 experimental replicates } \\
\hline $7 \mathrm{a}$ & 8.0 & $4 \%$ & $5.8 \%$ & $0.6 \%$ & $0.6 \%$ & $0.02 \%$ & $0.02 \%$ & $6 \%$ \\
\hline $7 b$ & 7.8 & $3 \%$ & $3.5 \%$ & $0.4 \%$ & $0.3 \%$ & $0.01 \%$ & $0.01 \%$ & $3 \%$ \\
\hline $7 \mathrm{c}$ & 8.0 & $2 \%$ & $2.8 \%$ & $0.4 \%$ & $0.2 \%$ & $0.01 \%$ & $<\mathrm{DL}$ & $1 \%$ \\
\hline $5 \mathrm{a}$ & 6.8 & $3 \%$ & $2.9 \%$ & $0.4 \%$ & $0.5 \%$ & $0.01 \%$ & $0.01 \%$ & $2 \%$ \\
\hline $5 b$ & 6.7 & $2 \%$ & $2.7 \%$ & $0.5 \%$ & $0.5 \%$ & $0.01 \%$ & $0.01 \%$ & $3 \%$ \\
\hline $5 c$ & 6.5 & $2 \%$ & $2.2 \%$ & $0.4 \%$ & $0.5 \%$ & $0.01 \%$ & $0.01 \%$ & $2 \%$ \\
\hline $3 a$ & 3.2 & $31 \%$ & $32 \%$ & $12 \%$ & $8.4 \%$ & $0.11 \%$ & $0.22 \%$ & $24 \%$ \\
\hline $3 b$ & 3.0 & $10 \%$ & $12 \%$ & $4.2 \%$ & $3.0 \%$ & $0.05 \%$ & $0.07 \%$ & $8 \%$ \\
\hline $3 c$ & 3.0 & $5 \%$ & $6.8 \%$ & $2.3 \%$ & $1.8 \%$ & $0.03 \%$ & $0.04 \%$ & $5 \%$ \\
\hline $1 \mathrm{a}$ & 1.2 & $8 \%$ & $10 \%$ & $5.0 \%$ & $3.4 \%$ & $0.30 \%$ & $1.03 \%$ & $10 \%$ \\
\hline $1 b$ & 1.1 & $1 \%$ & $1.1 \%$ & $1.5 \%$ & $2.2 \%$ & $0.22 \%$ & $0.36 \%$ & $3 \%$ \\
\hline $1 \mathrm{c}$ & 1.1 & $1 \%$ & $0.5 \%$ & $0.8 \%$ & $1.3 \%$ & $0.15 \%$ & $0.20 \%$ & $2 \%$ \\
\hline \multicolumn{9}{|c|}{ Absolute associated uncertainty } \\
\hline $7 \mathrm{a}$ & 1.6 & $2.5 \%$ & $3.7 \%$ & $0.6 \%$ & $0.5 \%$ & $0.06 \%$ & $0.07 \%$ & $2 \%$ \\
\hline $7 b$ & 1.2 & $0.5 \%$ & $0.5 \%$ & $0.1 \%$ & $0.1 \%$ & $0.04 \%$ & $0.05 \%$ & $1 \%$ \\
\hline $7 \mathrm{c}$ & 1.0 & $0.4 \%$ & $0.3 \%$ & $0.1 \%$ & $0.1 \%$ & $0.08 \%$ & $0.09 \%$ & $1 \%$ \\
\hline $5 \mathrm{a}$ & 0.7 & $0.5 \%$ & $0.5 \%$ & $0.1 \%$ & $0.0 \%$ & $0.01 \%$ & $0.03 \%$ & $1 \%$ \\
\hline $5 b$ & 0.4 & $0.3 \%$ & $0.3 \%$ & $0.1 \%$ & $0.1 \%$ & $0.04 \%$ & $0.05 \%$ & $1 \%$ \\
\hline $5 c$ & 0.4 & $0.2 \%$ & $0.2 \%$ & $0.1 \%$ & $0.1 \%$ & $0.04 \%$ & $0.04 \%$ & $1 \%$ \\
\hline $3 a$ & 0.2 & $3.5 \%$ & $3.9 \%$ & $1.9 \%$ & $1.5 \%$ & $0.05 \%$ & $0.04 \%$ & $5 \%$ \\
\hline $3 b$ & 0.3 & $1.2 \%$ & $0.9 \%$ & $0.5 \%$ & $0.5 \%$ & $0.01 \%$ & $0.03 \%$ & $2 \%$ \\
\hline $3 c$ & 0.3 & $0.8 \%$ & $0.6 \%$ & $0.2 \%$ & $0.3 \%$ & $0.00 \%$ & $0.03 \%$ & $3 \%$ \\
\hline 1a & 0.4 & $4.2 \%$ & $4.9 \%$ & $1.9 \%$ & $1.2 \%$ & $0.08 \%$ & $0.20 \%$ & $5 \%$ \\
\hline $1 b$ & 0.4 & $0.4 \%$ & $0.3 \%$ & $0.3 \%$ & $0.7 \%$ & $0.05 \%$ & $0.06 \%$ & $2 \%$ \\
\hline $1 \mathrm{c}$ & 0.4 & $0.3 \%$ & $0.1 \%$ & $0.3 \%$ & $0.6 \%$ & $0.04 \%$ & $0.04 \%$ & $2 \%$ \\
\hline DL & & $0.01 \%$ & $0.1 \%$ & $0.4 \%$ & $0.02 \%$ & $0.005 \%$ & $0.005 \%$ & $1 \%$ \\
\hline
\end{tabular}

for Saharan dust. Filgueras et al. (2002) reported the effect of acid leaching on exchangeable and sorbed metals, pointing out the absorbing properties of carbonates. Gleyzes et al. (2002) highlighted some dissolution of silicate at low pHs, but both works concluded that acid leaching does not dissolve oxides. Journet et al. (2008) showed that clays releases soluble iron at $\mathrm{pH} 1$. For the carbonated dust studied in this paper, we do not have enough data to clearly attribute the origin of the dissolved aluminium and iron to a specific solid phase, but a noticeable solubility increase at $\mathrm{pH} 3$ might attribute a part of soluble aluminium and iron to carbonated phases.

We can compare the solubility found here with that estimated and calculated in seawater during the DUNE mesocosm experiments, where the same soil fraction was used, but only after processing with synthetic cloud-like water to reproduce condensation-evaporation processes on dust particles during atmospheric transport (Wuttig et al., 2013). For manganese, iron, and aluminium, these authors reported sol-

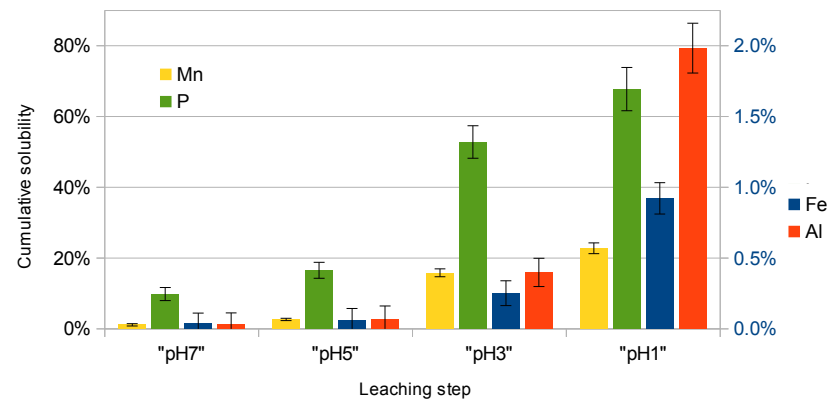

Figure 3. Cumulative solubility for $\mathrm{Mn}, \mathrm{P}$ (left scale), Fe, and Al (right scale). The vertical segments are the standard deviation of the four replicates.

ubilities that are respectively equal to $27-41,0.12$, and $1 \%$. In our work, the cumulated solubility of manganese remained low at the highest $\mathrm{pHs}$ and increased significantly at $\mathrm{pH}$ 3 , reaching a value of $16 \pm 1.5 \%$ (value \pm uncertainty). An 
additional increase of the solubility was observed for the last leaching step at $\mathrm{pH} 1$, with a maximum value of $23 \pm 2 \%$. For iron and aluminium, the cumulated solubility remained very low (less than $0.1 \%$ ) for the highest pHs. Starting from $\mathrm{pH} 3$, it approached the value observed in the mesocosms where a solubility of $0.25 \pm 0.14 \%$ and $0.4 \pm 0.15 \%$ was observed for iron and aluminium, respectively. At $\mathrm{pH} 1$, the observed cumulated solubility exceeded the solubilities calculated in the mesocosms. It is important to keep in mind that the calculated solubilities in the mesocosms were marred by a significant uncertainty. The average solubility similarities obtained from unprocessed dust at $\mathrm{pH} 3$ in water (this study) and cloud-processed dust in seawater (Wuttig et al., 2013) indicate that the acidic conditions encountered during the laboratory cloud processing (see Guieu et al., 2010) were recorded in the dust until it was used to seed the mesocosms. This recorded acidity controlled the solubility levels in seawater.

Using aerosols sampled on the SE Mediterranean coast, Herut et al. (1999) measured relative solubilities for $\mathrm{P}$ in seawater that were between 10 to $30 \%$ for air masses coming from Africa or Arabia. Ridame and Guieu (2002) measured $\mathrm{P}$ solubilities of 2 to $10 \%$ in seawater (after $6 \mathrm{~h}$ ) and 5 to $20 \%$ in fresh water (after $24 \mathrm{~h}$ ) for the finest fraction of soil collected in southern Algeria. Izquierdo et al. (2012) measured an average solubility of $11 \%$ in pure water for deposited Saharan dust collected on the NW Mediterranean coast. This solubility could increase up to $50 \%$ if the air masses are influenced by anthropogenic emissions. Bergametti et al. (1992) measured soluble and insoluble phosphorus in rainwater in Corsica. Phosphorus solubility was also low for natural dust and high for anthropogenic aerosols. Nenes et al. (2011) showed a strong increase in P solubility in Saharan dust, from 5-10\% up to $90 \%$ after a $24 \mathrm{~h}$ acid processing at $\mathrm{pH} 2$. Here, we find a solubility of $10 \%$ for "pH 7" and $55 \%$ at $\mathrm{pH}=3$. The "pH 7" solubility value is consistent with the dissolution experiments reported for nonpolluted air masses. The rise in solubility in the polluted air masses is similar to those observed here from $\mathrm{pH} 7$ to $\mathrm{pH} 3$. This increase could be caused by the presence of more soluble anthropogenic phosphorus in the collected aerosols, as well as processing of the dust by more acidic conditions. In the leaching experiments reported in this paper, phosphorus does not change, and therefore only acid processing caused the observed increase in solubility.

If we assume that the carbonates are completely dissolved at $\mathrm{pH} 3$, we can see in Fig. 3 that approximately $50 \%$ of phosphorus and $15 \%$ of manganese dissolved at that $\mathrm{pH}$ were most likely associated with carbonates in the fine fraction of the investigated soil. Despite the fact that the behaviour of iron is more complex, its $0.25 \%$ cumulated solubility at $\mathrm{pH} 3$ might represent its fraction associated with carbonates, in an undetermined form, that may be either adsorbed or included in the lattice, like manganese.

\section{Conclusions}

The fine fraction of the carbonate-rich soil from southern Tunisia used in this study has been shown to be representative of mineral dust aerosol transported and deposited in the northwestern Mediterranean region, especially in spring (Guieu et al., 2010). The observed solubility of various elements from this soil, with pHs down to 3 , highlights the importance of the carbonate fraction in the dissolution process. Trace elements such as manganese and phosphorus, which are micro-nutrients for marine organisms, appear to have a fraction that is associated with carbonates and that can be dissolved with the typical acidic conditions encountered in cloud water, without invoking extreme acidic conditions. This yields a high lability to mineral dust-contained phosphorus (50-55\% at $\mathrm{pH}=3$ for our sample), and indicates that the carbonate fraction and its composition should be used to model aeolian dust transport and the associated deposition of nutrients and micro-nutrients onto the surface of the ocean.

In regions affected by mineral dust transport, carbonate dissolution prevents the acidification of rainwater by anthropogenic gases, such as nitric or sulphuric acid (Losno et al., 1991), and therefore decreases the weathering strength of rain/cloud water. The weaker solubilisation of trace metals and phosphorus by a less acidic atmospheric water can be compensated by the release of carbonate, which appears as a potential source of bioavailable nutrients.

Acknowledgements. The authors thank E. Bon Nguyen, S. Triquet, M. Labiadh, and the Institute of Arid Regions of Medenine, Tunisia for their help. They also thank Sarah Mullin for improving the English content. This work was funded by the French ANR under the ANR-07-BLAN-0126-01 contract (DUNE project). DUNE was endorsed by the international SOLAS (Surface Ocean - Lower Atmosphere) programme in February 2009 (http://www.solas-int.org/activities/project-endorsement.html).

We thank CNRS-INSU and the Laboratoire d'Océanographie de Villefranche (LOV) for financing this publication.

Edited by: C. Guieu

\section{References}

Avila, A., Alarcon, M., Castillo, S., Escudero, M., Garcia-Orellana, J., Masque, P., and Querol, X.: Variation of soluble and insoluble calcium in red rains related to dust sources and transport patterns from North Africa to northeastern Spain, J. Geophys. Res., 112, D05210, doi:10.1029/2006JD007153, 2007.

Baker, A. R., Jickells, T. D., Witt, M., and Linge, K. L.: Trends in the solubility of iron, Aluminium, Manganese and Phosphorus in aerosol collected over the Atlantic Ocean, Mar. Chem., 98, 4358, 2006.

Bergametti, G., Gomes, L., Remoudaki, E., Desbois, M., Martin, D., and Buat Ménard, P.: Present transport and deposition patterns of African dusts to the north-western Mediterranean, in: Paleoclimatology and Paleometeorology: Modern and Past Patterns of 
Global Atmospheric Transport, edited by: Leinen, M. and Sarnthein, M., Kluwer Academic Publishers, Boston, 227-251, 1989.

Bergametti, G., Remoudaki, E., Losno, R., Steiner, E., Chatenet, B., and Buat-Ménard, P.: Source, transport and deposition of atmospheric phosphorus over the Northwestern Mediterranean, J. Atmos. Chem., 14, 501-513, 1992.

Buck, C. S., Landing, W. M., and Resing, J.: Pacific Ocean aerosols: Deposition and solubility of iron, aluminum, and other trace elements, Mar. Chem., 157, 117-130, doi:10.1016/j.marchem.2013.09.005, 2013.

Claquin, T., Schulz, M., and Balkanski, Y. J.: Modeling the mineralogy of atmospheric dust sources, J. Geophys. Res., 104, $22243-$ 22256, 1999.

Desboeufs, K. V., Losno, R., Vimeux, F., and Cholbi, S.,: The pH dependent dissolution of wind-transported Saharan dust, J. Geophys. Res., 104, 21287-21299, 1999.

Desboeufs K. V., Losno, R., and Colin, J. L.: Factors influencing aerosol solubility during cloud processes, Atmos. Environ., 35, 3529-3537, 2001.

Desboeufs, K. V., Losno, R., and Colin, J. L.: Figures of merit of pneumatic and ultrasonic sample introduction systems in inductively coupled plasma-multichannel-based emission spectrometry in an ultra-clean environment, Anal Bioanal. Chem., 375, 567-573, 2003.

Desboeufs, K., Leblond, N., Wagener, T., Nguyen, E. B., and Guieu, C.: Chemical fate and settling of mineral dust in surface seawater after atmospheric deposition observed from dust seeding experiments in large mesocosms, Biogeosciences Discuss., 11, 49094947, doi:10.5194/bgd-11-4909-2014, 2014.

Filgueiras, A. V., Lavilla, I., and Bendicho, C.: Chemical sequential extraction for metal partitioning in environmental solid samples, J. Environ. Monit., 4, 823-857, 2002.

Fujiwara, S.: Investigation of Trace Impurities in Solids by Electron Paramagnetic Resonance. Distribution of Manganese in Calcium Carbonate, Anal. Chem., 36, 2259-2261, doi:10.1021/ac60218a012, 1964.

Gleyzes, C., Tellier, S., and Astruc, M.: Fractionation studies of trace elements in contaminated soils and sediments: a review of sequential extraction procedures, TrAC-Trend. Anal. Chem., 21, 451-467, 2002.

Guieu, C., Dulac, F., Desboeufs, K., Wagener, T., Pulido-Villena, E., Grisoni, J.-M., Louis, F., Ridame, C., Blain, S., Brunet, C., Bon Nguyen, E., Tran, S., Labiadh, M., and Dominici, J.-M.: Large clean mesocosms and simulated dust deposition: a new methodology to investigate responses of marine oligotrophic ecosystems to atmospheric inputs, Biogeosciences, 7, 27652784, doi:10.5194/bg-7-2765-2010, 2010.

Guieu, C., Dulac, F., Ridame, C., and Pondaven, P.: Introduction to project DUNE, a DUst experiment in a low Nutrient, low chlorophyll Ecosystem, Biogeosciences, 11, 425-442, doi:10.5194/bg11-425-2014, 2014.

Heimburger, A., Tharaud, M., Monna, F., Losno, R., Desboeufs, K., and Bon Nguyen, E., SLRS-5 elemental concentrations of thirty-three uncertified elements deduced from SLRS-5/SLRS-4 ratios, Geostand. Geoanal. Res., 37, 77-85, doi:10.1111/j.1751908X.2012.00185.x, 2013.

Herut, B., Krom, M. D., Pan, G., and Mortimer, R., Atmospheric input of nitrogen and phosphorus to the Southeast Mediterranean:
Sources, fluxes, and possible impact, Limnol. Oceanogr., 44, 1683-1692, 1999.

Izquierdo, R., Claudia, R., Benítez-Nelson, C. R., Masqué, P., Castillo, S., Alastuey, A., and Avila, A.: Atmospheric phosphorus deposition in a near-coastal rural site in the NE Iberian Peninsula and its role in marine productivity, Atmos. Environ., 49, 361370, 2012.

Journet, E., Desboeufs, K. V., Caquineau, S., and Colin, J. L.: Mineralogy as a critical factor of dust iron solubility, Geophys. Res. Lett., 35, L07805, doi:10.1029/2007GL031589, 2008.

Kandler, K., Benker, N., Bundke, U., Cuevas, E., Ebert, M., Knippertz, P., Rodriguez, S., Schütz, L., and Weinbruch, S.: Chemical composition and complex refractive index of saharan mineral dust at Izaña, Tenerife (Spain) derived by electron microscopy, Atmos. Environ., 41, 8058-8074, 2007.

Kitano, Y., Okumura, M., and Idogaki, M.: Uptake of phosphate ions by calcium carbonate, Geochem. J., 12, 29-37, 1978.

Losno, R., Bergametti, G., Carlier, P., and Mouvier, G.: Major ions in marine rainwater with attention to sources of alkaline and acidic species, Atmos. Environ., 25, 763-770, 1991.

Nenes, A., Krom, M. D., Mihalopoulos, N., Van Cappellen, P., Shi, Z., Bougiatioti, A., Zarmpas, P., and Herut, B.: Atmospheric acidification of mineral aerosols: a source of bioavailable phosphorus for the oceans, Atmos. Chem. Phys., 11, 6265-6272, doi:10.5194/acp-11-6265-2011, 2011.

Nezat, C. A., Blum, J. D., Yanai, R. D., and Hamburg, S. P.: A sequential extraction to determine the distribution of apatite in granitoid soil mineral pools with application to weathering at the Hubbard Brook Experimental Forest, NH, USA, Appl. Geochem., 22, 2406-2421, 2007.

Ridame, C. and Guieu, C., Saharan input of phosphate to the oligotrophic water of the open western Mediterranean Sea, Limnol. Oceanogr., 47, 856-869, 2002.

Sholkovitz, E. R., Sedwick, P. N., Church, T. M., Baker, A. R., and Powell, C. F.: Fractional solubility of aerosol iron: Synthesis of a global-scale data set, Geochim. Cosmochim. Ac., 89, 173-189, doi:10.1016/j.gca.2012.04.022, 2012.

Yeghicheyan, D., Carignan, J., Valladon, M., Bouhnik Le Coz, M., Le Cornec, F., Castrec-Rouelle, M., Robert, M., Aquilina, L., Aubry, E., Churlaud, C., Dia, A., Deberdt, S., Dupré, B., Freydier, R., Gruau, G., Hénin, O., De Kersabiec, A.-M., Macé, J., Marin, L., Morin, N., Petitjean, P., and Serrat, E.: A compilation of silicon and thirty-one trace elements measured in the natural river water reference material SLRS-4 (NRC-CNRC), Geostandards Newsletter, 25, 465-474, 2001.

Yeghicheyan, D., Bossy, C., Bouhnik-Coz, M. Douchet, C., Granier, G. Heimburger, A., Lacan, F., Lanzanova, A., Rousseau, T., Seidel, J.-L., Tharaud, M., Candaudap, F., Chmeleff, J., Cloquet, C., Delpoux, S., Labatut, M., Losno, R., Pradoux, C., Sivry, Y., and Sonke, J. E.: A Compilation of Silicon, Rare Earth Element and Twenty-One other Trace Element Concentrations in the Natural River Water Reference Material SLRS-5 (NRC-CNRC), Geostand. Geoanal. Res., 37, 449-467, doi:10.1111/j.1751908X.2013.00232.x, 2013.

Wuttig, K., Wagener, T., Bressac, M., Dammshäuser, A., Streu, P., Guieu, C., and Croot, P. L.: Impacts of dust deposition on dissolved trace metal concentrations ( $\mathrm{Mn}, \mathrm{Al}$ and $\mathrm{Fe}$ ) during a mesocosm experiment, Biogeosciences, 10, 2583-2600, doi:10.5194/bg-10-2583-2013, 2013. 